\title{
Building Resilience in Teacher Education: An Evidenced Informed Framework
}

Dr Caroline Mansfield (Corresponding author)

Murdoch University ${ }^{\mathrm{a}}$

90 South Street, Murdoch

Western Australia 6150

Australia

caroline.mansfield@murdoch.edu.au

+61893602467

Dr Susan Beltman

Curtin University ${ }^{\mathrm{b}}$

GPO Box U1987, Perth

Western Australia 6845

Australia

s.beltman@curtin.edu.au

Dr Tania Broadley

Curtin University ${ }^{\mathrm{b}}$

GPO Box U1987, Perth

Western Australia 6845

Australia

t.broadley@curtin.edu.au

Dr Noelene Weatherby-Fell

University of Wollongong ${ }^{c}$

Northfields Avenue, Wollongong

New South Wales 2522

Australia

noelene@uow.edu.au 


\begin{abstract}
This paper proposes a framework for building resilience in teacher education. The framework is informed by a focused review of relevant literature to determine factors that may be addressed in teacher education to support teacher resilience and ways in which this may occur. Findings show that personal and contextual resources along with use of particular strategies all contribute to resilience outcomes and that many of these can be developed in teacher education. Using these findings, a comprehensive resilience framework is proposed with five overarching themes - understanding resilience, relationships, wellbeing, motivation and emotions. Implementation possibilities are discussed.
\end{abstract}

\title{
Keywords
}

Teacher resilience, teacher education, pre-service teachers, wellbeing, motivation

\section{Highlights}

- Presents an evidence-based framework for building resilience in teacher education

- Reviews literature over 15 years identifying key factors associated with teacher resilience

- Identifies personal and contextual resources, strategies and outcomes of the resilience process

- Discusses implementation possibilities in teacher education

\section{Introduction}

A desired outcome of teacher education programs is to develop graduates who will be high quality teachers, experiencing job satisfaction and enjoyment in their work as well as maintaining their motivation, commitment and enthusiasm for many years. While this outcome may be realised for some graduates, internationally there is concern in some countries (such as the United Kingdom, United States and Australia) about rates of teacher attrition. The first five years of a teacher's career may be a time of particular vulnerability, with estimates of $40-50 \%$ of early career teachers in many countries leaving the profession during that time (Gallant \& Riley, 2014). Studies exploring why teachers leave have pointed 
to teacher stress and burnout (Kyriacou, 2011; Schlichte, Yssel, \& Merbler, 2005) and inadequate pre-service preparation for the reality of teachers' work (Demetriou, Wilson, \& Winterbottom, 2009).

An alternative approach to the issue of teacher attrition has been to focus on why teachers remain in the profession, the factors that sustain them, the resources they harness to navigate through challenges, and consequently how they may develop resilience and thrive rather than simply survive in their work (Beltman, Mansfield, \& Price, 2011). This change is in line with other broad movements such as the positive psychology literature (see, for example, Reivich, Seligman, \& McBride, 2011; Yates \& Masten, 2004). Research projects focusing specifically on teacher resilience have been conducted in the United Kingdom (e.g. Sammons, Day, Kington, Gu, Stobart, \& Smees, 2007), Ireland (e.g. Morgan, 2011), Australia (e.g. Mansfield, Beltman, Price, \& McConney, 2012; Johnson, et al., 2014), Europe (e.g. Wosnitza, et al., 2013) and South Africa (e.g. Ebersohn 2012; 2014). Internationally, there is consensus that particular personal resources (e.g. motivation, social and emotional competence) and use of coping strategies (e.g. problem solving, goal setting, maintaining work-life balance) enable teachers to demonstrate resilience.

While research has identified many personal and contextual resources that are important for teacher resilience, and recommendations have been made at the individual, school and system levels (see, for example, Day \& Gu, 2014; Johnson, et al., 2014), fewer studies point to specific ways teacher education may make a positive contribution to the development of teacher resilience. Some suggestions about content and learning experiences in teacher education have been made (see, for example, Castro, Kelly, \& Shih, 2010), but studies of teacher resilience at the pre-service level are limited. While it is acknowledged that the resources teachers use to enable resilience are influenced by life experience and career stage, there seems to be agreement that teacher education may play a critical role in the resilience process. Day and Gu (2014) have cogently argued that: "efforts to increase the quality of teaching and raise standards of learning and achievement for all pupils must focus on efforts to build, sustain and renew teacher resilience, and that these efforts must take place in initial teacher training" (p. 22).

Even so, given the complexity and multifaceted nature of resilience, how this might occur and the specific possibilities for teacher education remain unclear. The aim of this paper is to 
propose a framework for building resilience in teacher education. To ensure the framework is informed by current research, the starting point is a review of teacher resilience literature to clarify the significance of teacher resilience, identify the factors that have been shown to be important for teacher resilience and draw together the implications for teacher education. These findings are then used to develop a comprehensive, evidence-based framework for teacher education. Possibilities for operationalisation of the framework are discussed.

\subsection{Teacher quality, teacher education and resilience}

It has been argued that teacher resilience is a 'quality retention' issue (Day \& Gu, 2010) whereby retention of committed, engaged and motivated teachers who, regardless of career stage, continue to develop professionally and maximise their capacity to provide high quality teaching. A large research project in the UK found that where teachers were committed and resilient, their students were more likely to attain levels at or above those expected in the UK national testing program (Day, 2008), and that individual teacher characteristics mattered more in accounting for differences in pupil progress than did characteristics of schools (Sammons, et al., 2007). Resilient teachers have been described as those who have the capacity to thrive in difficult circumstances, are skilled in behaviour management, able to empathise with difficult students, able to restrain negative emotions and focus on the positive, experience a sense of pride and fulfilment and increased commitment to their school and profession (Howard \& Johnson, 2004).

Teacher quality has also recently been placed at the forefront of educational initiatives concerning student outcomes, teacher accountability and ongoing professional learning in many countries. To improve teacher quality, governments have mandated reforms in teacher education and trialled alternative approaches to teacher training. Standards for teaching have been developed and teacher education providers have been required to meet particular accreditation requirements. Research highlights the importance of resilience in teacher quality (Day \& Gu, 2014), yet often teacher resilience and wellbeing do not feature in such reforms.

To provide context for the work undertaken in this paper, the situation of teacher education in Australia illustrates some of the above key issues. In Australia, like many countries, teacher accountability measures have increased along with national regulation of teacher education and the teaching profession (Mayer, 2014). A recently formed Teacher Education Ministerial 
Advisory Group (TEMAG) stated their intention to "lift the quality and status of the teaching profession" and their belief "that action needs to start when teachers are gaining their qualifications" (Australian Government, 2014, p 1). To gain accreditation, teacher education providers must demonstrate how their programs address the Australian Professional Standards for Teachers (APST) (AITSL, 2014a) at the graduate level as well as meet mandatory curriculum, pedagogical and professional experience course requirements. These external pressures on teacher education curriculum have reduced the control individual universities have on their curriculum and in some instances 'squeezed out' particular content. The APST makes explicit the knowledge, practice and professional engagement required across teachers' careers (AITSL, 2014a) and is comprised of 37 individual specific standards across 7 broader standards. With regard to teacher resilience and wellbeing, the standards refer to capacity for managing some potential challenges (such as difficult student behaviour), but there are no standards that directly refer to teachers' capacity to manage their own emotions and wellbeing. Such capacity is widely acknowledged as important in the literature on emotional intelligence and other aspects of emotions (see, for example, Chan 2008; Corcoran \& Tormey, 2012), as well as being of crucial importance for teachers in the current age of accountability (Day, 2008; Newberry, Gallant, \& Riley, 2013).

In addition, the Australian National Curriculum requires teachers to teach Personal and Social Capabilities (ACARA, 2012) including skills such as self-awareness (recognition of emotions, self-knowledge, self-perception, self-worth and reflective practice), selfmanagement (appropriate expression of emotions, self-discipline, goal setting and tracking, working independently and showing initiative, confidence, resilience and adaptability), social awareness (empathy, appreciating diverse perspective, contributing to civil society, advocacy for and service to others, understanding relationships) and social management (communication, working collaboratively, decision making, conflict resolution and negotiation, building and maintaining relationships, leadership) (ACARA, 2012). Such skills are also widely acknowledged in the broader resilience literature (Beltman et al., 2011). Teachers, are expected to teach and model these capabilities both in classroom lessons and in daily interactions with students, colleagues and members of the broader community, yet such capabilities are not specifically addressed in the standards for teacher education programs, nor the APST. Many schools in Australia also have particular programs focused on student mental health and wellbeing, such as KidsMatter (www.kidsmatter.edu.au), and teachers are required to implement such programs. It cannot necessarily be assumed that pre-service 
teachers have the skills and strategies to take care of their own wellbeing and to enable their personal resilience. A major concern therefore is how pre-service teachers may develop these resilience related skills in order to effectively teach and model such capabilities in their future careers as teachers, for their own benefit and for the benefit of their future students and colleagues.

Although the Australian example may have features that are particularly unique to that context, there are features of this example that are common to other countries. The need to adhere to teaching standards is common as is concern that teacher education has been impacted by "top-down, often evidence-light but ideology-heavy" approaches (Gilroy, 2014, p. 445). In discussing teacher education in the United States over the last forty years, Bullough (2014, p. 474) noted the "politicisation of education and teacher education" and the "loss of teacher educator control of programmes and programme content." In the United Kingdom, Murray and Passy (2014) voiced concern for teacher educators about how to assist future teachers cope with "the demands of future curricular, pedagogical changes and the new roles and responsibilities" (p. 492) that will emerge in the profession. It is our contention that in a profession with increasing demands, teacher resilience can positively influence outcomes for teachers and students.

\subsection{Resilience in pre-service teacher education}

Calls for teacher education to be "relevant, rigorous and responsive" (Cefai \& Cavioni, 2014, p. 144), in the context of these issues, affirms the need for resilience to be a part of teacher education, yet there are few examples of how this may occur. At one level, resilience related skills and strategies can be viewed as an essential component of developing teacher competence, may be part of teacher competency frameworks, and as such may develop through typical university and school-based experiences. Yet concern about teacher attrition and burnout suggests that for some teacher candidates this may not suffice and a more explicit, directed approach to skills and strategies that support resilience may be beneficial. What is less clear in the literature are the particular approaches that may be used and specific concepts that may be addressed. Furthermore, because there are many concepts related to resilience an in-depth examination of these is needed to develop a comprehensive framework to encompass all key aspects, reducing the risk of haphazard approaches. This paper contributes to the field by synthesising the extant literature to develop an evidence-based (from the literature) framework for resilience in pre-service teacher education. 
Whilst the challenges facing teachers as they go about their work have been widely documented, research also indicates that the nature of pre-service courses may present additional stressors. Gardner (2011) reported research indicating that university students have greater levels of psychological distress than the general population and studies have reported success with online resilience interventions in higher education (see, for example, Ryan, Shochet, \& Stallman, 2014). All teacher education courses include periods of practical experiences in schools and this can be an especially stressful time as students encounter the realities of teaching. For example, Goldstein (2005) found that student teachers experienced a sense of disillusionment from the "contrast between idealised images and realities of the profession" (p. 7). Developing teacher education curriculum to build resilience in pre-service teachers is advantageous for teachers themselves, as well as future employers and school students. Resilience-focused curricular at university may also form the basis for ongoing personal development through existing professional development programs. As Gardner (2011) suggested, "universities could consider the potential of developing preventative selfhelp and well-being programs for future student-teachers' wellbeing” (p. 24).

\subsection{Conceptualising resilience}

The term 'resilience' or 'resilient' has become commonly used in everyday language and so it is important to clarify what 'resilience' means in the context of the teaching profession. Early definitions of resilience focused on identifying the particular risk and protective factors that enabled or constrained resilience and particular traits that characterised resilient individuals. Definitions of resilience have included not just recovery from stress to a previous level of health but of sustained growth as a result of a healthy response to stressful situations (Reich, Zautra, \& Hall, 2010). In recent years researchers have begun to conceptualise resilience from a social ecological perspective whereby resilience is "defined as a set of behaviours over time that reflect the interactions between individuals and their environments, in particular the opportunities for personal growth that are available and accessible" (Ungar, 2012, p. 14).

In the context of the teaching profession, resilience may be conceptualised as a capacity, a process and also as an outcome. Resilience involves the capacity of an individual teacher to harness personal and contextual resources to navigate through challenges, the dynamic 
process whereby characteristics of individual teachers and of their personal and professional contexts interact over time as teachers use particular strategies, to enable the outcome of a teacher who experiences professional engagement and growth, commitment, enthusiasm, satisfaction, and wellbeing (Beltman, 2015). Pre-service teachers may develop capacity for resilience through building personal resources (e.g. motivation; social and emotional competence), understanding ways to mobilise contextual resources (e.g. relationships, support networks), and developing a range of adaptive coping strategies (e.g problem solving, time management, maintaining work-life balance) to manage challenges with a view to maximising adaptive, resilient outcomes (e.g. commitment, job satisfaction, wellbeing, engagement). This paper examines the recent literature to discover how this may be achieved.

\section{Method}

\subsection{Review process}

The review process included an online literature search of major databases (A+Education, Academic One File, ERIC, ProQuest, SAGE Journals) with the following criteria:

- Keywords, and/or title and/or abstract including 'teach' and 'resilience' or 'resilient'

- Published between 2000-2014;

- Regarding the resilience of teachers and/or pre-service teachers; and

- Text types to include peer reviewed journal articles and book chapters from edited books. As the key purpose of teacher education is to prepare prospective teachers for their future practice, studies of resilience of practicing teachers were included in the review. The resulting set of seventy-one texts comprised two book chapters and sixty-nine peer-reviewed journal articles.

\subsection{Data analysis}

Data analysis occurred in three phases. The first phase involved a careful examination of each paper to identify the following: keywords (given by authors), aim of the paper, methodology, participants, data source(s), resilience related factors discussed, key findings and implications for teacher education. Resilience related factors were factors that authors mentioned as influencing resilience including personal factors (such as sense of vocation and purpose), contextual factors (such as relationships with colleagues) and strategies associated with resilience (such as problem solving and help-seeking). A table was used to summarise this 
information. Four researchers who had background knowledge and experience in the field of teacher resilience took part in this phase, each examining a minimum of 10 papers.

Second, the list of resilience-related factors was examined and words were grouped into 'like' groups, so that "colleagues, collegial support, collegial relationships" became "relationships with colleagues" and "emotion regulation, emotional challenge, emotional competence, emotional resilience, emotional support" became "emotional awareness and regulation". Researchers involved in phase 1 worked together in this phase to ensure agreement about factors. After this process, 51 resilience-related factors were used to begin the next phase of analysis.

The third phase of analysis involved using QSR International's NVivo 10 software to further interrogate the papers and code text discussing each of the factors and implications for teacher education. Because of the large number of papers use of NVivo software enabled data to be easily organised and coded. Each of the papers was imported into NVivo and relevant text coded according to the particular factor discussed, as identified in the previous phases. The table created in phase 1 was also imported to cross-reference information. Text search queries were used to confirm the findings in phase 1. Care was taken in the text searches to account for spelling differences (i.e. humour and humor), to review words that have been used for similar meanings (for example, colleagues and peers), and to include stemmed words in the search parameters (i.e. commit, commitment, committed). The context of each word was also reviewed to ensure the word reflected the description of each factor. In line with our conceptualisation of teacher resilience, factors were grouped as personal resources, contextual resources, strategies and resilience outcomes. Of the 71 papers, 61 described personal resources, 69 described contextual resources, 55 described resilience strategies, and 58 discussed the outcomes of resilience. An overview of these is shown in Table 1. 
Table 1: overview of resilience factors (number of papers)

\begin{tabular}{|c|c|c|c|}
\hline Personal Resources & Contextual Resources & Strategies (52) & Outcomes (58) \\
\hline (61) & (68) & 15 factors & 10 factors \\
\hline 12 factors & 14 factors & & \\
\hline motivation (35) & school leaders (41) & work-life balance (28) & wellbeing (42) \\
\hline efficacy (29) & colleagues (31) & problem solving (23) & commitment (35) \\
\hline sense of purpose (21) & $\begin{array}{l}\text { Relationships with } \\
\text { students (26) }\end{array}$ & $\begin{array}{l}\text { professional learning } \\
\text { (13) }\end{array}$ & job satisfaction (27) \\
\hline optimism (19) & school culture (25) & goal setting (13) & agency (23) \\
\hline $\begin{array}{l}\text { social and emotional } \\
\text { competence (11) }\end{array}$ & mentors (25) & $\begin{array}{l}\text { setting boundaries } \\
\text { (13) }\end{array}$ & enthusiasm (16) \\
\hline initiative (11) & trust (19) & reflection (13) & $\begin{array}{l}\text { sense of belonging } \\
\text { (15) }\end{array}$ \\
\hline sense of vocation (10) & recognition (18) & humour (11) & responsibility (15) \\
\hline hope (9) & autonomy (17) & communication (11) & passion (12) \\
\hline empathy (9) & family support (17) & help-seeking (10) & enjoyment (11) \\
\hline $\begin{array}{l}\text { high expectations ( } 7 \text { ) } \\
\text { value (6) }\end{array}$ & $\begin{array}{l}\text { social networks (16) } \\
\text { opportunities for } \\
\text { participation (9) }\end{array}$ & $\begin{array}{l}\text { faith practices ( } 8) \\
\text { time management }(8)\end{array}$ & engagement (8) \\
\hline \multirow[t]{2}{*}{ courage (4) } & $\begin{array}{l}\text { emotional support (8) } \\
\text { collaboration (7) }\end{array}$ & $\begin{array}{l}\text { persistence }(6) \\
\text { emotional regulation } \\
\text { (6) }\end{array}$ & \\
\hline & $\begin{array}{l}\text { induction programs } \\
\text { (2) }\end{array}$ & $\begin{array}{l}\text { seeking opportunity } \\
\text { for renewal (5) } \\
\text { mindfulness (2) }\end{array}$ & \\
\hline
\end{tabular}

\section{Findings}

\subsection{What factors have been identified in the literature as important for teacher}

\section{resilience?}

In presenting the findings for this question an overview of the key factors as shown in Table 1 is provided. Discussing each factor in detail is beyond the scope of this paper, rather the purpose in identifying the factors is to show the range of factors involved in enhancing resilience and use these to build an evidence-based framework for supporting the 
development of resilience in teacher education. Analysis of the literature generated a list of 51 factors that were seen as either contributing to or occurring as a result of teacher resilience.

\subsubsection{Personal resources}

The twelve factors identified in personal resources were related to two main themes of motivations and emotions. Motivation was the personal resource most frequently referred to with 26 papers describing motivation, "inner drive" (Hong, 2012) or intrinsic motivation (Kitching, Morgan, \& O'Leary, 2009) as being important for resilience. Efficacy was the second most prevalent personal resource with papers emphasising the importance of selfbelief in pre-service (Le Cornu, 2009) and in-service [practicing] teachers (Howard \& Johnson, 2004) which can be enhanced as teachers encounter and overcome, perhaps with support, the challenges they face in their teaching (Gu \& Day, 2007). Other factors associated with motivation were as sense of purpose, in particular a sense of 'moral purpose' (Day, 2014; Sumsion, 2004), which can act as a buffer against burnout (MacKenzie, 2012; Meister $\&$ Ahrens, 2011). Hong (2012) argued that a sense of vocation is essential for teacher resilience and Gu and Day (2007) stated its importance for teacher quality. Initiative is also important for teachers in how they exercise a sense of agency and address challenges (Cameron \& Lovett, 2014).

Personal resources associated with emotions were also described. Optimism was discussed (Tait, 2008), with specific reference to academic optimism - a feature of enabling school cultures and resilient principals (Day, 2014). Hope (Huisman, Singer, \& Catapano, 2010), empathy (Jennings, Snowberg, Coccia, \& Greenberg, 2011) and social and emotional competence (Ee \& Chang, 2010) were also described as protective factors. Le Cornu (2013) explained how courage, or "the capacity to move into situations when we feel fear or hesitation" (p. 7) featured in the resilience of early career teachers.

\subsubsection{Contextual resources}

A major theme in the literature regarding contextual resources for teacher resilience was the importance of relationships both within and outside the working context. Citing Jordan's model of relational resilience, Le Cornu (2013) argued that strengthening relationships is critical for enhancing resilience, especially among early career teachers. Relational resilience is formed through a web of strong and trusting relationships between teacher-leaders, 
teachers-teachers, and students-teachers, and emphasises the importance of mutual empowerment, growth and support at the centre of the resilience process (Day \& Gu, 2014; $\mathrm{Gu}, 2014)$.

Teacher-leader relationships was the most commonly mentioned contextual resource (Bobek, 2002; Day, 2008; 2014; Howard \& Johnson, 2004). Relationships were enhanced when school leaders recognised the achievements of teachers and offered support and encouragement to "stretch and grow" (Cameron \& Lovett, 2014, p. 154). Meister and Ahrens (2011) found that for their veteran teachers, leaders "who recognized these teachers' abilities and strengths and provided autonomy and support were the ones who enhanced the teachers' enthusiasm and inspired them to grow as professionals" (p. 774). In current times school leaders themselves are also in need of personal and contextual resources to sustain their professional resilience (Day, 2014; Steward, 2014).

Teacher-teacher relationships were also crucial (Brunetti, 2006; O'Sullivan, 2006) with trusted colleagues available for daily debriefing being able to "boost morale because they know what you are going through and can help keep your spirits up" (Howard \& Johnson, 2004, p. 413). Hong (2012) argued that such relationships are important for teacher efficacy, which in turn influences the outcomes of commitment, resilience and retention. Fellow teachers can provide non-judgemental support and a reality check (Papatraianou \& Le Cornu, 2014). In her research in South African schools, Ebersöhn (2012), used the term

'Relationship Resourced Resilience (RRR)' to emphasise that resilience occurs as a collective process whereby individuals 'flock' together to access, mobilise and share resources for positive adaptation in adverse conditions. Relationships are therefore important both for individual and collective resilience.

Although the literature reports variation in the quality of mentors (Mansfield, Beltman, \& Price, 2014), positive relationships with mentors have been shown to influence early career teachers' efficacy and satisfaction (Castro et al., 2010; Ee \& Chang, 2010) and identity (Hong, 2012). School culture also plays a role in the resilience process (Peters \& Pearce, 2012). Schools that promote resilience and wellbeing for staff have been characterised by supportive administration and colleagues, collaboration, opportunities for meaningful participation and contribution to the decision making process (Cameron \& Lovett, 2014; Johnson et al., 2014). Elements of trust, autonomy, collegiality and leadership are critical to 
resilience-promoting school cultures (Gu, 2014; Malloy \& Allen, 2007) as well as emotional support which can have a buffering effect in times of challenge (Keogh, Garvis, \& Prendergast, 2012).

Of particular note for this paper, is the finding that various support networks play an important role in early career teacher resilience. Support networks are important for new teachers working in remote areas (Sharplin, O’Neill, \& Chapman, 2011; Sullivan \& Johnson, 2012) and supportive peer networks may be established while pre-service teachers are still at university (Keogh, Garvis, Pendergast, \& Diamond, 2012). Support networks may include inschool, outside school, and/or online supports that may assist teachers in overcoming challenges (Papatraianou \& Le Cornu, 2014). Positive students-teacher relationships can also be important in sustaining teachers (Castro, et al., 2010; Doney, 2012; Gu \& Day, 2007; Morgan, Ludlow, Kitching, O’Leary, \& Clarke, 2010).

\subsubsection{Strategies}

Fifteen strategies were important for teacher resilience. Problem solving was the most frequent, with twenty papers outlining problem solving approaches (Castro et al., 2010) and problem solving styles (Dolati, Emamipuor, \& Kushki, 2014). Collaborative problem solving was noted as important for early career teachers (Johnson, et al., 2014) as well as helpseeking (Sharplin, et al., 2011) which can sometimes be challenging for beginning teachers (Mansfield et al., 2012).

Particular strategies that assist with wellbeing were also described, especially those associated with maintaining a work-life balance (Johnson et al., 2014; Le Cornu, 2013). Tait (2008) argued that teachers who were resilient actively took care of themselves as, for example, they could recognise their own stress levels and take steps to reduce this through physical activity or social networking. Engaging in ongoing professional learning was seen as an important strategy for enhancing resilience especially if it responded to teachers' interests, needs and aspirations (O’Sullivan, 2006; Patterson, Collins, \& Abbott; 2004) and involves reflection (Leroux, \& Théorêt, 2014). Professional learning also provided an important avenue for professional renewal and rejuvenation (Castro et al., 2010). Teachers "need to be supported by professional communities of colleagues, immersed in reflective intellectual inquiry into their practice, and given opportunities for leadership development within their professional contexts" (Yonezawa, Jones, \& Singer, 2011, p. 926). The benefits of goal 
setting, and striving for short and long term goals (Sharplin et al., 2011), which could be part of a wellness plan and ongoing professional development (Curry \& O'Brien, 2012) were noted. Being able to communicate effectively with parents, colleagues and the school community was also an important strategy (Bobek, 2002; Schelvis, Zwetsloot, Bosa, \& Wiezer, 2014; Sharplin et al., 2011). Setting emotional boundaries to prevent stress and burnout was a strategy used by teachers staying in the profession (Hong, 2012) and having clear boundaries enabled teachers to feel secure, take risks and enabled autonomy (Meister \& Ahrens, 2011).

Strategies that promote positive emotions also featured in the literature. These included humour (Doney, 2012), which enabled early career teachers to endure "negative emotions and gain a sense of emotional control” (Sharplin et al., 2011, p. 142). Curry and O'Brien (2012, p. 182) described humour as part of "creative wellness". Other papers mentioned practices of faith, such as prayer, in wellbeing (e.g. Curry \& O'Brien, 2012; Yates, Pelphrey, $\&$ Smith, 2008) and providing a protective resource for teachers (Ebersöhn, 2014). Emotion regulation was also noted as an important coping strategy for teachers (Morgan, 2011) and Tait (2008, p. 69) suggested that novice teachers who "demonstrated high degrees of resilience, personal efficacy, and emotional intelligence" were able to recognise and manage their own levels of stress. Mindfulness was suggested as a strategy to help reduce stress, and improve emotion regulation and health, enabling teachers to reach their potential (Jennings, et al., 2011).

\subsubsection{Outcomes}

Teacher wellbeing was the most frequent outcome associated with resilience in the literature. The 10 resilience outcomes identified in 48 papers could also be described as motivational and emotional. For example, factors such as commitment, job satisfaction, agency, engagement and belonging are outcomes of being motivated. Pretsch, Flunger and Schmitt (2012) found that measures of resilience predicted the outcomes of wellbeing and job satisfaction and suggested that "resilience as a personal resource buffers the effects of the special occupational challenges of the teaching profession" (p. 331). As well as being an important personal resource (seen as perhaps a sense of purpose), commitment is both a condition for teaching and an outcome of experiences as a teacher (Day, 2008). Leadership practices in schools, especially where teachers feel valued, respected, supported to develop their expertise and experience agency are associated with commitment and job satisfaction 
(Cameron \& Lovett, 2014). Keogh et al. (2012) argued that agency, efficacy and resilience work together in that agency assists teachers manage challenges, which in turn enhances selfefficacy and consolidates resilience. Factors such as passion, enthusiasm and enjoyment reflect positive emotional states which were also reported as critical to teacher resilience and intentions to remain in the profession (Le Cornu, 2013; Tait, 2008).

\subsection{Implications for teacher education}

The previous section presented an overview of the range of personal and contextual resources, strategies and outcomes that have been associated with teacher resilience in the literature, but what role might teacher education play in assisting prospective teachers to build resilience?

Twenty-three papers made recommendations for pre-service teacher education curriculum in terms of developing personal resources and strategies. These included particular coping strategies such as problem solving (Castro et al., 2010; Huisman et al., 2010). Thieman, Henry and Kitchel (2012) suggested that teacher education should proactively educate teachers on coping resources, time management, and stress management techniques. Ee and Chang (2010) proposed that assertiveness training would be useful for pre-service teachers to enable them to "advocate for themselves, work effectively with admin, colleagues and parents and ask for the support and assistance they need on the job" (p. 329). These authors also argued that emotional competencies (for example, self-regulation, motivation, empathy) and social skills should form part of the teacher education experience. Prospective and practicing teachers should have professional development about how to handle emotions, "respond to emotionally charged situations or how to recover from emotional trauma" (Hong, 2012, p. 434). Tait (2008) suggested that resilience-building activities in pre-service and induction programs should include: systematically teaching social skills, assertiveness training, self-regulation, empathy, and motivation. With regard to motivation, Prosser (2008) suggested that during their pre-service preparation, teachers need time to explore their motivations (emotional, political, metaphysical, or religious) for teaching.

Recommendations were also made regarding the content of teacher education programs especially with regard to building capacity for managing specific contextual challenges. Mansfield et al., (2014) argued that pre-service teachers should be prepared for the multiple 
challenges of the profession and have opportunities to develop personal resources (such as coping skills, stress management and problem solving skills) to help manage challenging situations. Tait (2008) similarly had suggested that assertiveness training, social skills, selfregulation and empathy were areas that pre-service and induction programs needed to address. Gu and Day (2013) posited that pre-service teachers need to be more aware of the potential challenges they may encounter in the profession, such as children's misbehaviour (Gibbs \& Miller, 2013). The papers also identified some areas where teacher preparation was found to be lacking such as for teaching multi-age classes and indigenous students competently and with confidence (Sullivan \& Johnson, 2012).

Providing strategies and knowledge of resources to address particular contextual challenges was also noted. Huisman et al., (2010) argued that teacher education should provide opportunities for developing sociocultural awareness. As a result of a series of studies conducted with teachers in poverty stricken rural schools in South Africa, Ebersöhn (2012) argued that the South African teacher education curriculum should prepare future teachers for "the chronic and cumulative nature of risk in poverty" (p. 24) and build awareness of resources including personal traits such as optimism, perseverance, pragmatism and collaboration, as well as prepare them for the "constancy of adaptation" (p. 25) required in resource-constrained societies. In Australia, researchers have suggested that pre-service teachers need to be prepared to teach in rural and remote areas (Trinidad, et al., 2013) and to face the challenges of such contexts (Sullivan \& Johnson, 2012).

\subsection{What kinds of teacher education experiences help build resilience?}

As well as noting particular content that may contribute to building resilience in teacher education, some authors also recommended particular learning experiences that would be useful. One frequent suggestion was to connect pre-service teachers more directly to the 'real' world of teachers through direct contact and through practical examples such as in case studies and videos. For example, Tait (2008) said that opportunities to learn about the social nature of teaching and to recognise their own resilient responses should be given. By "working with scenarios, videos, or actual classroom observations" to examine challenging situations "teacher candidates could identify and practice coping strategies, emotional competence, reframing skills, and other resilient behaviours and ways of thinking" (p. 71). Feedback and mentoring from teachers who have successfully navigated their early career experience would also have benefits (Hong, 2012). 
Use of case studies in teacher education has been suggested as a way to help pre-service teachers develop resilience skills. Case studies can guide pre-service teachers "through action research oriented projects and encouraging more advanced methods of problem solving" (Castro et al., 2010, p. 629) and be useful to show examples of pragmatic innovations to promote resilience (Ebersöhn, 2012). Scenarios can also be used to prompt discussion about resilient responses as well as "identify and practice coping strategies, emotional competence, reframing skills and other resilient behaviours of thinking” (Ee \& Chang, 2010, p. 329).

Other papers suggested that teacher education courses provide opportunities for prospective teachers to discuss their professionalism, ways to manage parents and colleagues and other aspects of the workplace (Castro et al., 2010). Reflection can also include the use of selfassessment tools that can be used in implementing a wellness plan, as illustrated by Curry and O’Brien (2012) which helped "provide stability, a focus on internal locus of control, and support to new teachers in the school to career transition" (p. 184). Such tools may be useful in identifying potential burnout concern, areas of strength, physical and emotional health, and can be used by individuals for ongoing reflection and personal development throughout their career.

Another way teacher education courses can address some of the known factors related to resilience is through facilitating the development of support networks. Building support networks during teacher education was acknowledged as important (Castro et al., 2010; Tait, 2008) as teacher education colleagues can provide valuable support for each other in the early career stages. Baker-Doyle (2011) argued that teacher education programs should explicitly address the ways in which beginning teachers can develop strong supportive networks, and social networking could be used "to foster resiliency among the younger teachers entering the workforce” (Muller, Gorrow, \& Fiala, 2011, p. 553). Papatraianou and Le Cornu (2014) agreed that teacher educators can help identify particular individuals or social networks, inside of school, outside of school, or online, which will be most beneficial in enabling teachers to overcome workplace challenges.

This section has presented findings from the literature review and in doing so, illustrated the many factors related to resilience and the many recommendations and suggestions for teacher education that have been made. It is clear however from the papers reviewed, that the 
recommendations are simply suggestions and, with the exception of Le Cornu (2009), there have been no studies that aimed at building resilience resources and strategies with preservice teachers. One possible reason for this lies in the complexity of the resilience construct and the lack of an evidence based framework that clearly indicates particular skills and strategies to be developed and ways this may occur in teacher education.

\section{Discussion: Building the BRiTE framework}

The current literature confirms that the resilience process is multifaceted and involves a variety of personal and contextual resources interacting in a dynamic manner over time. Furthermore, the outcomes of resilience contribute to efficacy for resilience, or beliefs about capabilities to cope with setbacks (Morgan, 2011), which influence future resilient outcomes. Researchers in the field are agreed that the place to start building resilience lies in teacher education, specifically with assisting prospective teachers to develop the personal resources and strategies for managing particular challenges, yet there are few specific examples of how this might be done. Table 1 shows the myriad of factors that influence teacher resilience, yet to build a framework that can be operationalized in teacher education, overarching themes emerging from the literature also need to be identified.

We propose that, as well as knowledge about resilience, four key themes are important to consider for building teacher resilience, those being relationships, wellbeing, motivation and emotions. Table 2 shows how the evidence from the literature (Table1) can be organised according to each theme and shows suggested topics that may be used in teacher education. The right hand column gives examples of the types of activities that may be suitable across themes. We suggest that this BRiTE framework may provide a conceptually driven approach to building resilience in teacher education. 
Table 2: Building Resilience in Teacher Education: The BRiTE framework

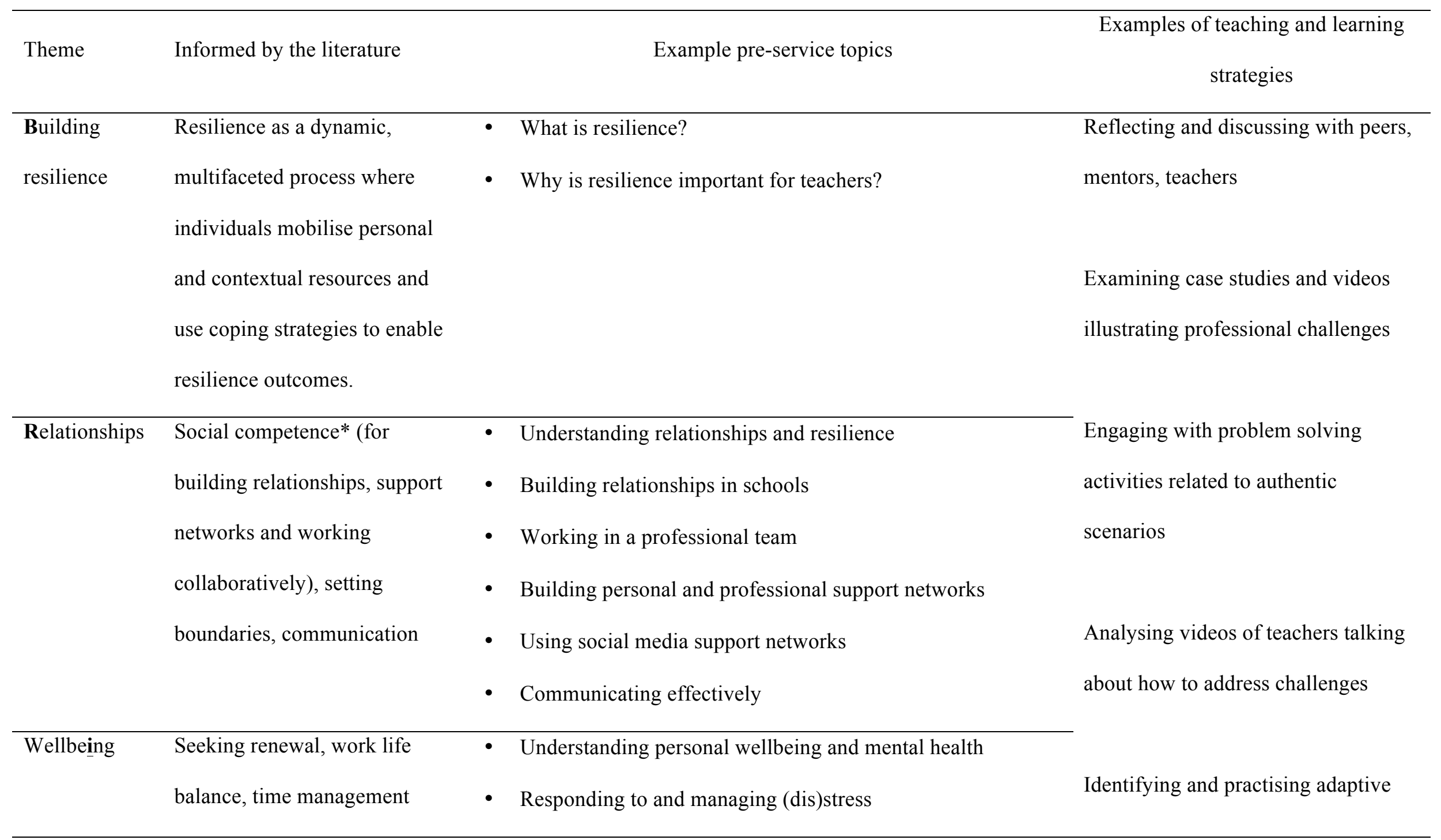

Mansfield, C. F., Beltman, S., Broadley, T., \& Weatherby-Fell, N. (2016). Building resilience in teacher education: An evidenced informed framework. Teaching and Teacher Education, 54, 77-87. doi:10.1016/j.tate.2015.11.016 
- Managing work-life balance

- Time management

Practising reframing skills and

\begin{tabular}{lllll}
\hline Motivation & Efficacy, value, sense of & - & Maintaining motivation & optimistic thinking \\
& purpose, sense of vocation, & - & Persistence and efficacy & Practising effective communication \\
& initiative, high expectations, & - & Problem solving processes & skills for a range of situations \\
& problem solving, professional & - & Goal setting and management & Reflecting on personal resources and \\
& learning, goal setting, help & - & Help seeking & strategies via self-assessment tools \\
& seeking, reflection, persistence & - & Ongoing professional learning & and planning for self-development \\
\hline Emotions & Emotional competence*, & - Emotional awareness & Conducting action research projects
\end{tabular}

* 'Social and emotional competence' as shown in Table 1, has been separated into 'social competence' and 'emotional competen 
It should be noted that contextual resources that may be harnessed in schools are not included in the framework, however, an awareness of the importance of contextual resources is essential when pre-service teachers are in schools. Each of the above aspects that could be enhanced during pre-service courses will be briefly discussed with these points in mind.

\subsection{Building resilience: Conceptual underpinnings}

Pre-service teachers should develop a strong conceptual understanding of resilience, specifically its dynamic and multifaceted nature. This means not only appreciating personal strengths and limitations, but developing awareness of the contextual resources and coping strategies that can promote resilience. Understanding the process of resilience can also promote a sense of agency in times of challenge (e.g. Keogh et al., 2012) and encourage action rather than focusing on personal limitations. As pre-service teachers learn about children's social and emotional development they should also develop an understanding of their own resilience. Pre-service teachers should also understand that resilience develops over time and with experience, and will have different manifestations depending on individual and context. Building resilience should be viewed as building capacity and providing opportunity for ongoing learning and improvement and be incorporated into the curriculum of pre-service teacher education. Resilience should not be understood as simply a personal trait but as a complex process that involves both personal and contextual factors (Gu \& Day, 2013).

\subsection{Relationships}

The critical role of relationships in the resilience process cannot be underestimated as illustrated in the literature by the increasing use of discussions about 'relational resilience' (e.g. Gu, 2014; Le Cornu, 2013). Social competence is an important personal resource for the development of relationships, which are developed in school contexts through interactions with colleagues, mentors, and school leaders, and outside school with family, friends and social networks. Pre-service teachers need to know how to establish relationships in new environments, perhaps using case studies and scenarios or videos of new teachers indicating how they managed to do this. Communication skills and strategies are important for developing supportive relationships, engaging effectively with students and their families, and managing challenging interactions. Pre-service teachers can be encouraged to join professional networks and to develop collegial social networking pages while still in their 
course. Such resources can be helpful once commencing teaching and the outcomes of supportive relationships include a sense of belonging, engagement and responsibility.

\subsection{Wellbeing}

Wellbeing, an individual's physical, emotional and psychological health (Ferguson, 2008) is linked to the previous themes as it requires an awareness of emotions and motivations. Various programs exist in the US that promote resilience in teachers and focus, for example, on stress reduction through yoga or on developing emotional competence (Fleming, Mackrain, \& LeBuffe, 2013). Physical wellbeing is a topic that could be incorporated into teacher education curriculum through physical and health education. As already indicated, teacher self-care is not an integral part of current professional standards. Professional wellbeing requires the use of deliberate strategies such as setting boundaries, reflection, goal setting, maintaining work-life balance, time management and seeking renewal /rejuvenation (e.g. Thieman et al., 2012). Wellbeing can also be enhanced in resilience enabling contexts where school leaders have support strategies for staff, and where staff work together to build each other's wellbeing. Teacher wellbeing is another important resilience-related outcome.

\subsection{Motivation}

Motivation is an important trigger for initial career choice, is related to personal resources such as sense of purpose and vocation, efficacy and initiative, and is another key aspect of resilience (e.g. Hong, 2012). Motivational strategies include goal setting and seeking professional learning. Motivation can be enhanced through contextual resources such as relationships with others, recognition from others (school leaders, colleagues, parents, students), supportive school cultures, trust, being given autonomy and opportunities for meaningful participation, so there is an important link to the theme of knowing how to build relationships. Outcomes of motivation include sustained commitment, job satisfaction, a sense of agency and enhanced efficacy.

\subsection{Emotions}

Emotions feature prominently in the literature on teacher resilience (e.g. Mansfield et al., 2012; Kirk \& Wall, 2010; Steward, 2014). Emotional competence and emotional intelligence are seen as important personal resources as well as the presence of optimism, hope, empathy and courage. Pre-service and beginning teachers need an awareness and knowledge about emotions; to be emotionally competent, recognising their own emotions and how they impact 
on self and others; and also the capacity to consider the emotions of others. Strategies to generate positive emotions, such as reframing situations, using humour to reduce emotional tension or provide a different perspective in difficult situations, mindfulness, and conscious emotional management, can be taught. School contexts can be emotionally supportive where staff morale is high and relationships are positive - again the link to relationships. Emotion related outcomes include factors such as enjoyment of work, enthusiasm and passion (e.g. Le Cornu, 2013).

\subsection{Implementing the framework: possibilities}

There is a range of possibilities for implementing the BRiTE framework in teacher education, depending on the particular teacher education context. Issues such as length of programme, programme accreditation requirements, resources available and modes of delivery (fully online, blended or face-to-face) will influence how the framework may be used.

Face-to-face workshops or seminars are perhaps the most typical mode of delivery and resources could be developed to provide information, enable personal reflection, encourage problem solving and discussion related to 'real world' teaching challenges. Typically face-toface workshops are supported by textbooks that could include a chapter or section on teacher resilience and wellbeing (see, for example, Beltman, 2015). In line with current trends in higher education, online learning resources and activities about teacher resilience may also be developed as a stand-alone resource or to supplement or complement face-to-face learning. An advantage of online learning is that it can be personalised by addressing the learning path of each individual student (Johnson, Adams Becker, Estrada, \& Freeman, 2014) and users may engage in learning at most relevant and convenient times (rather than on a day/time set by a university timetable) and may revisit ideas of interest over time and when the need arises. Moreover, much teacher professional development is available through online platforms. For example, the Australian Institute for Teaching and School Leadership (AITSL) leads the recent work around professional standards for teachers and uses an online platform to provide tools to support teacher self-assessment and monitoring as well as professional development (AITSL, 2014b). Such developments are indicative of the growing trend for quality learning experiences to be facilitated in an online mode.

The BRiTE (Building Resilience in Teacher Education) (www.brite.edu.au) learning modules, provide one example of how online interactive resources may support teacher 
resilience. The five modules in this resource are personalised, interactive, grounded in the literature and connected to the profession. The modules are personalised through the inclusion of self-quizzes and the facility to copy and save items of interest, thus building a personal 'toolkit' of resilience strategies. Learning activities include video cases, scenarios and problem solving activities, opportunities for reflection, along with videos of 'real' teachers talking about resilience-related issues and managing challenges. Throughout the modules 'what do the experts say?' sections provide the research evidence informing the module so users have opportunity to understand the research and conceptual underpinnings of the content. Suggested methods of implementing the modules are also provided and teacher educators are free to develop their own. For example, in a blended learning environment, preservice teachers could work on one topic and then bring their responses to an online scenario to a face-to-face workshop to discuss. Another example of blending the online with face-toface components could be that pre-service teachers interview an experienced teacher regarding some of their strategies and compare these with strategies in the online videos or tips. Therefore, consistent with recent initiatives in higher education, providing an online, personalised, dynamic, interactive, professionally connected and evidence driven approach to building resilience has potential benefits.

\section{Conclusion}

Based on evidence from the teacher resilience literature a comprehensive framework for building resilience in teacher education has been developed. The framework has four overarching themes (relationships, wellbeing, motivation and emotions) and a conceptual underpinning of teacher resilience. Implementation possibilities include face-to-face, blended or online approaches. In the context of teacher education in Australia an online resource has been developed. The potential benefits and limitations of such a resource are yet to be determined and would provide the basis of future research.

There are a number of other important avenues for future research. Given that building resilience is a complex process, research may investigate which overarching themes or resources may have the most positive impact on teacher resilience. Furthermore, particular resources may be more important than others at different career stages. Longitudinal research would help explore the development of resilience resources and strategies over time. Another issue that needs further research is the extent to which engagement with learning activities 
designed to build capacity for resilience may have a temporary or sustained influence on resilience outcomes such as commitment, motivation, job fulfilment and wellbeing.

On a cautionary note, it is important that a personal resources based approach does not exclude the critical role played by contextual resources provided within schools and by employing bodies. Although resilience tends to be mentioned in the literature regarding teacher attrition, it would be remiss to associate attrition with low levels of professional resilience or to assume that teachers leaving the profession lack resilience. The possibility that some school contexts may be particularly adverse for some individuals, and that a resilient response may be to leave should not be precluded. Such possibilities call for a more nuanced understanding of the relationship between attrition and resilience.

Consideration should also be given to the degree to which pre-service educators already possess and can model some of the skills suggested or have the capacity to provide resources needed by their students. This paper has highlighted the importance of resilience for teachers and the lack of specific resilience-focused curriculum in teacher education programs. The proposed evidence based online modules could offer a useful resource and offer one strategy for addressing some of the challenges faced by graduate teachers as they enter the profession.

\section{Acknowledgement}

Support for this research has been provided by the Australian Government Office for Learning and Teaching, grant number ID13-2924. The views expressed in the publication do not necessarily reflect the views of the Australian Government Office for Learning and Teaching.

\section{References}

ACARA (Australian Curriculum, Assessment and Reporting Authority), (2012). General capabilities in the Australian Curriculum. Retrieved from http://www.acara.edu.au

AITSL (Australian Institute for Teaching and School Leadership) (2014a). Organisation of the Standards. Victoria: Educational Services Australia. Retrieved from http://www.aitsl.edu.au/australian-professional-standards-forteachers/standards/overview/organisation-of-the-standards 
AITSL (Australian Institute for Teaching and School Leadership) (2014b). Victoria: Educational Services Australia. Retrieved from http://www.aitsl.edu.au

Australian Government (2014). Teacher Education Ministerial Advisory Group. Retrieved from http://docs.education.gov.au/node/36789

Baker-Doyle, K. (2011). The networked teacher: How new teachers build social networks for professional support. New York, NY: Teachers College Press.

Beltman, S. (2015). Teacher professional resilience: Thriving not just surviving. In

N. Weatherby-Fell (Ed.), Learning to teach in the secondary school (pp. 20-38).

Melbourne, Aust: Cambridge University Press.

Beltman, S., Mansfield, C., \& Price, A. (2011). Thriving not just surviving: a review of research on teacher resilience. Educational Research Review, 6, 185-207. http:// dx.doi.org/10.1016/j.edurev.2011.09.001.

Biggs, J., \& Moore, P. J. (1993). The process of learning (3rd ed.). Sydney: Prentice Hall.

Bobek, B. L. (2002). Teacher resiliency: A key to career longevity. The Clearing House, 75(4), 202-205. doi: 10.1080/00098650209604932

Brunetti, G. J. (2006). Resilience under fire: Perspectives on the work of experienced, inner city high school teachers in the United States. Teaching and Teacher Education, 22(7), 812-825. doi: 10.1016/j.tate.2006.04.027

Bullough, R. V. (2014). Recalling 40 years of teacher education in the USA: A personal essay. Journal of Education for Teaching, 40(5), 474-491. doi: $10.1080 / 02607476.2014 .956537$

Cameron, M., \& Lovett, S. (2014). Sustaining the commitment and realising the potential of highly promising teachers. Teachers and Teaching, 21(2), 150-163. doi: $10.1080 / 13540602.2014 .928132$

Castro, A. J., Kelly, J., \& Shih, M. (2010). Resilience strategies for new teachers in highneeds areas. Teaching and Teacher Education, 26(3), 622-629. doi: 10.1016/j.tate.2009.09.010

Cefai, C., \& Cavioni, V. (2014). From neurasthenia to eudaimonia: Teachers' well-being and resilience. In C. Cefai \& V. Cavioni (Eds.), Social and emotional education in 
primary school: Integrating theory and research into practice (pp. 133-148). New York: Springer Science+Business Media. doi: 10.1007/978-1-4614-8752-4.

Chan, D. W. (2008). Emotional intelligence, self-efficacy, and coping among Chinese prospective and in-service teachers in Hong Kong. Educational Psychology, 28(4), 397-408.

Corcoran, R. P., \& Tormey, R. (2012). How emotionally intelligent are pre-service teachers? Teaching and Teacher Education, 28(5), 750-759. doi:10.1016/j.tate.2012.02.007

Curry, J. R., \& O'Brien, E. R. (2012). Shifting to a wellness paradigm in teacher education: A promising practice for fostering teacher stress reduction, burnout resilience, and promoting retention. Ethical Human Psychology and Psychiatry, 14(3), 178-191. doi: 10.1891/1559-4343.14.3.178

Day, C. (2008). Committed for life? Variations in teachers' work, lives and effectiveness. Journal of Educational Change, 9(3), 243-260. doi: 10.1007/s10833-007-9054-6

Day, C. (2014). Resilient principals in challenging schools: The courage and costs of conviction. Teachers and Teaching, 20(5). 638-654. doi:

$10.1080 / 13540602.2014 .937959$

Day, C., \& Gu, Q. (2010). The new lives of teachers. London: Routledge Taylor \& Francis Group.

Day, C., \& Gu, Q. (2014). Resilient teachers, resilient schools: Building and sustaining quality in testing times. Oxon, UK: Routledge.

Demetriou, H., Wilson, E., \& Winterbottom, M. (2009). The role of emotion in teaching: are there differences between male and female newly qualified teachers' approaches to teaching? Educational Studies, 35(4), 449-473. doi: 10.1080/03055690902876552

Dolati, S., Emamipuor, S., \& Kushki,S. (2014). The relationship between problem solving and resilience with job satisfaction in female teachers. Applied Psychology, 2(9), 3646. http:// www. Jourpsyc.com

Doney, P. A. (2012). Fostering resilience: A necessary skill for teacher retention. Journal of Science Teacher Education. 24, 645-664. doi: 10.1007/s10972-012-9324-x 
Ebersöhn, L. (2012). Adding 'flock' to 'fight and flight': A honeycomb of resilience where supply of relationships meets demand for support. Journal of Psychology in Africa, 27(1), 29-42. doi: 10.1080/14330237.2012.10874518

Ebersöhn, L. (2014). Teacher resilience: theorizing resilience and poverty. Teachers and Teaching, 20(5), 568-594. doi: 10.1080/13540602.2014.937960

Ee, J., \& Chang, A. (2010). How resilient are our graduate trainee teachers in Singapore? The Asia-Pacific Education Researcher, 19(2), 321-331.

Ferguson, D. (2008). What teachers need to know about personal wellbeing. Melbourne: ACER Press.

Fleming, J. L., Mackrain, M., \& LeBuffe, P. A. (2013). Caring for the caregiver: Promoting the resilience of teachers. In S. Goldstein \& R. B. Brooks (Eds.), Handbook of resilience in children. New York: Springer Science+Business Media.

Gallant, A., \& Riley, P. (2014). Early career teacher attrition: new thoughts on an intractable problem. Teacher Development, 18(4), 562-580. doi: 10.1080/13664530.2014.945129

Gardner, S. (2011). Stress among prospective teachers: A review of the literature. Australian Journal of Teacher Education, 36(1), 18-28. doi: 10.14221/ajte.2010v35n8.2

Gibbs, S., \& Miller, A. (2013). Teachers' resilience and well-being: A role for educational psychology. Teachers and Teaching: Theory and Practice, 20(5), 609-621. doi: $10.1080 / 13540602.2013 .844408$

Gilroy, P. (2014). International teacher education: Changing times, changing practices. Journal of Education for Teaching, 1-2. doi: 10.1080/02607476.2014.957995

Goldstein, L.S. (2005). Becoming a teacher as a hero's journey: Using metaphor in preservice teacher education. Teacher Education Quarterly, 32(1), 7-24.

Gu, Q. (2014). The role of relational resilience in teachers' career-long commitment and effectiveness. Teachers and Teaching: Theory and Practice, 20(5), 502-529. doi: 10.1080/13540602.2014.937961

Gu, Q., \& Day, C. (2013). Challenges to teacher resilience: Conditions count. British Educational Research Journal, 39(1), 22-44. doi: 10.1080/01411926.2011.623152

Gu, Q., \& Day, C. (2007). Teachers resilience: A necessary condition for effectiveness. Teaching and Teacher Education, 23, 1302-1316. doi: 10.1016/j.tate.2006.06.006 
Hong, J. Y. (2012). Why do some beginning teachers leave the school, and others stay? Understanding teacher resilience through psychological lenses. Teachers and Teaching: Theory and Practice, 18(4), 417-440. doi: 10.1080/13540602.2012.696044

Howard, S., \& Johnson, B. (2004). Resilient teachers: Resisting stress and burnout. Social Psychology of Education, 7(4), 399-420.

Huisman, S., Singer, N. R., \& Catapano, S. (2010). Resiliency to success: Supporting novice urban teachers. Teacher Development: An International Journal of Teachers' Professional Development, 14(4), 483 - 499. doi: 10.1080/13664530.2010.533490

Jennings, P. A., Snowberg, K. E., Coccia, M. A., \& Greenberg, M. T. (2011). Improving classroom learning environments by Cultivating Awareness and Resilience in Education (CARE): Results of two pilot studies. The Journal of Classroom Interaction, 46(1), 37-48.

Johnson, L., Adams Becker, S., Estrada, V., Freeman, A. (2014). NMC Horizon Report: 2014 Higher Education Edition. Austin, Texas: The New Media Consortium. Retrieved from New Media Consortium: http://cdn.nmc.org/media/2014-nmc-horizon-report-heEN-SC.pdf

Johnson, B., Down, B., Le Cornu, R., Peters, J., Sullivan, A., Pearce, J., \& Hunter, J. (2014). Promoting early career teacher resilience: A framework for understanding and acting. Teachers and Teaching: Theory and Practice, 20(5), 530-546. doi: $10.1080 / 13540602.2014 .937957$

Keogh, J., Garvis, S., Pendergast, D., \& Diamond, P. (2012). Self-determination: Using agency, efficacy and resilience (AER) to counter novice teachers' experiences of intensification. Australian Journal of Teacher Education, 37(8), 46-65. doi: $10.14221 /$ ajte. $2012 \mathrm{v} 37 \mathrm{n} 8.3$

Kirk, J., \& Wall, C. (2010). Resilience and loss in work identities: A narrative analysis of some retired teachers' work-life histories. British Educational Research Journal, 36(4), 627-641. doi: 10.1080/01411920903018216

Kitching, K., Morgan, M., \& O'Leary, M. (2009). It's the little things: Exploring the importance of commonplace events for early-career teachers' motivation. Teachers and Teaching: Theory and Practice, 15(1), 43-58. doi: 10.1080/13540600802661311 
Kyriacou, C. (2011). Teacher stress: From prevalence to resilience. In J. Langan-Fox \& C. L. Cooper (Eds.), Handbook of stress in the occupations (pp. 161-173). Cheltenham, UK: Edward Elgar Publishing Inc.

Le Cornu, R. (2009). Building resilience in pre-service teachers. Teaching and Teacher Education, 25(5), 717-723. doi:10.1016/j.tate.2008.11.016

Le Cornu, R. (2013). Building early career teacher resilience: The role of relationships. Australian Journal of Teacher Education, 38(4), 1-16. doi: $10.14221 /$ ajte. $2013 \mathrm{v} 38 \mathrm{n} 4.4$

Leroux, M. \& Théorêt, M. (2014). Intriguing empirical relations between teachers' resilience and reflection on practice. Reflective Practice: International and Multidisciplinary Perspectives, 15(3), 289-303. doi: 10.1080/14623943.2014.900009

Mackenzie, S. (2012). 'I can't imagine doing anything else': Why do teachers of children with SEN remain in the profession? Resilience, rewards and realism over time. Journal of Research in Special Educational Needs, 12(3), 151-161. doi: 10.1111/j.1471-3802.2011.01221.x

Malloy, W. W., \& Allen, T. (2007). Teacher retention in a teacher resiliency-building rural school. The Rural Educator, 28(2), 19-27.

Mansfield, C. F., Beltman, S., \& Price, A. (2014). 'I'm coming back again!' The resilience process of early career teachers. Teachers and Teaching, 20(5), 547-567. doi:10.1080/13540602.2014.937958.

Mansfield, C. F., Beltman, S., Price, A., \& McConney, A. (2012). "Don't sweat the small stuff:" Understanding teacher resilience at the chalkface. Teaching and Teacher Education, 28, 357-367. doi:10.1016/j.tate.2011.11.001.

Mayer, D. (2014). Forty years of teacher education in Australia: 1974-2014. Journal of Education for Teaching, 40(5), 461-473. doi: 10.1080/02607476.2014.956536

Meister, D. G., \& Ahrens, P. (2011). Resisting plateauing: Four veteran teachers’s stories. Teaching and Teacher Education, 27(4), 770-778. doi: 10.1016/j.tate.2011.01.002

Morgan, M. (2011). Resilience and recurring adverse events: Testing an assets-based model of beginning teachers' experiences. The Irish Journal of Psychology, 32(3-4), 92-104. doi: 10.1080/03033910.2011.613189 
Morgan, M., Ludlow, L., Kitching, K., O'Leary, M., \& Clarke, A. (2010). What makes teachers tick? Sustaining events in new teachers' lives. British Educational Research Journal, 36(2), 191-208. doi: 10.1080/01411920902780972

Muller, S. M., Gorrow, T. R., \& Fiala, K. A. (2011). Considering protective factors as a tool for teacher resiliency. Education, 131(3), 545-555.

Murray, J., \& Passy, R. (2014). Primary teacher education in England: 40 years on. Journal of Education for Teaching, 40(5), 492-506. doi: 10.1080/02607476.2014.956542

Newberry, M., Gallant, A., \& Riley, P. (2013). Emotion and school: Understanding how the hidden curriculum influences relationships, leadership, teaching, and learning. Bingley, UK: Emerald.

O'Sullivan, M. (2006). Professional lives of Irish physical education teachers: Stories of resilience, respect and resignation. Physical Education and Sport Pedagogy, 11(3), 265-284. doi: 10.1080/17408980600986314

Papatraianou, L. H., \& Le Cornu, R. (2014). Problematising the role of personal and professional relationships in early career teacher resilience. Australian Journal of Teacher Education, 39(1), 100-106. doi: 10.14221/ajte.2014v39n1.7

Patterson, K., Collins, L., \& Abbott, G. (2003). Resilience and renewal: Urban teachers' restoration. International Journal of Learning, 10(2003), 1373-1385.

Peters, J., \& Pearce, J. (2012). Relationships and early career teacher resilience: A role for school principals. Teachers and Teaching: Theory and Practice, 18(2), 249-262. doi: $10.1080 / 13540602.2012 .632266$

Pretsch, J., Flunger, B., \& Schmitt, M. (2012). Resilience predicts well-being in teachers, but not in non-teaching employees. Social Psychology of Education, 15(3), 321-336. doi: $10.1007 / \mathrm{s} 11218-012-9180-8$

Prosser, B. (2008). The role of the personal domain in middle years teachers' work. Australian Journal of Middle Schooling, 8(2), 11-16.

Reich, J. W., Zautra, A. J., \& Hall, J. S. (eds.) (2010). Handbook of adult resilience. New York: Guilford Press.

Reivich, K. J., Seligman, M. E. P., \& McBride, S. (2011). Master Resilience Training in the U.S. Army. American Psychologist, 66(1), 25-34. doi:10.1037/a0021897 
Ryan, M. L., Shochet, I. M., \& Stallman, H. M. (2014). Universal online interventions might engage psychologically distressed university students who are unlikely to seek formal help. Advances in Mental Health, 9(1), 73-83. doi: 10.5172/jamh.9.1.73

Sammons, P., Day, C., Kington, A., Gu, Q., Stobart, G., \& Smees, R. (2007). Exploring variations in teachers' work, lives and their effects on pupils: Key findings and implications from a longitudinal mixed-method study. British Educational Research Journal, 33(5), 681-701. doi: 10.1080/01411920701582264

Schelvis, R. M. C., Zwetsloot, G. I. J. M., Bos, E. H., \& Wiezer, N. M. (2014). Exploring teacher and school resilience as a new perspective to solve persistent problems in the educational sector. Teachers and Teaching, 20(5), 622-637. doi:

$10.1080 / 13540602.2014 .937962$

Schlichte, J., Yssel, N., \& Merbler, J. (2005). Pathways to burnout: Case studies in teacher isolation and alienation. Preventing School Failure, 50(1), 35-40. doi: 10.3200/PESL.50.1.35-40

Sharplin, E., O'Neill, M., \& Chapman, A. (2011). Coping strategies for adaptation to new teacher appointments: Intervention for retention. Teaching and Teacher Education, 27(1), 136-146. doi: 10.1016/j.tate.2010.07.010

Steward, J. (2014). Sustaining emotional resilience for school leadership. School Leadership \& Management, 34(1), 52-68. doi: 10.1080/13632434.2013.849686

Sullivan, A., \& Johnson, B. (2012). Questionable practices? Relying on individual teacher resilience in remote schools. Australian and International Journal of Rural Education, 22(3), 101-116.

Sumsion, J. (2004). Early childhood teachers' constructions of their resilience and thriving: A continuing investigation. International Journal of Early Years Education, 12(3), 275290. doi: $10.1080 / 0966976042000268735$

Tait, M. (2008). Resilience as a contributor to novice teacher success, commitment, and retention. Teacher Education Quarterly, 35(4), 57-76.

Thieman, E. B., Henry, A. L., \& Kitchel, T. (2012). Resilient agricultural educators: Taking stress to the next level. Journal of Agricultural Education, 53(1), 81-94. doi: 10.5032/jae.2012.01081 
Trinidad, S., Broadley, T., Terry, E., Boyd, D., Lock, G., Sharplin, E., \& Ledger, S. (2013). Regional resilience: Pre-service teacher preparation to teach in the bush. Australian and International Journal of Rural Education, 23(2), 43-52.

Ungar, M. (Ed.). (2012). The social ecology of resilience: A handbook of theory and practice. New York: Springer.

Wosnitza, M., Morgan, M., Nevralova, K. Cefai, C. Henkel, M. Peixoto, F., Beltman, S. \& Mansfield, C. (2013). Keeping Cool Europe - Enhancing TeacherREsilience in Europe. Application Lifelong Learning Programme. Submission number 539590LLP-1-2013-1-DE-COMENIUS-CMP.

Yates, T. M., \& Masten, A. S. (2004). Fostering the future: Resilience theory and the practice of positive psychology. In P. A. Linley \& S. Joseph (Eds.). Positive psychology in practice. (pp. 521-539). Hoboken, NJ: John Wiley \& Sons.

Yates, L., Pelphrey, B. A., \& Smith, P. A. (2008). An exploratory phenomenological study of African American male pre-service teachers at a historical black university in the midsouth. National Forum of Applied Educational Research Journal, 21(3), 1-16.

Yonezawa, S., Jones, M., \& Singer, N. R. (2011). Teacher resilience in urban schools: The importance of technical knowledge, professional community, and leadership opportunities. Urban Education, 46(5), 913-931. doi: 10.1177/0042085911400341 